\title{
Enhanced reduction in cell viability by hyperthermia induced by magnetic nanoparticles
}

This article was published in the following Dove Press journal:

International Journal of Nanomedicine

I5 February 201 I

Number of times this article has been viewed

\author{
Héctor L Rodríguez-Luccioni \\ Magda Latorre-Esteves \\ Janet Méndez-Vega \\ Orlando Soto \\ Ana R Rodríguez \\ Carlos Rinaldi \\ Madeline Torres-Lugo
}

Department of Chemical Engineering, University of Puerto Rico, Mayagüez

0068I, Puerto Rico
Correspondence: Madeline Torres-Lugo Department of Chemical Engineering, University of Puerto Rico,

Mayagüez Campus,

PO Box 9000, Mayagüez

0068I, Puerto Rico

Tel +l 7878324040 (ext 2585)

Email madeline@ece.uprm.edu

\begin{abstract}
Colloidal suspensions of iron oxide magnetic nanoparticles are known to dissipate energy when exposed to an oscillating magnetic field. Such energy dissipation can be employed to locally raise temperature inside a tumor between $41^{\circ} \mathrm{C}$ and $45^{\circ} \mathrm{C}$ (hyperthermia) to promote cell death, a treatment known as magnetic fluid hyperthermia (MFH). This work seeks to quantify differences between MFH and hot-water hyperthermia (HWH) in terms of reduction in cell viability using two cancer cell culture models, Caco-2 (human epithelial colorectal adenocarcinoma) and MCF-7 (human breast cancer). Magnetite nanoparticles were synthesized via the co-precipitation method and functionalized with adsorbed carboxymethyl dextran. Cytotoxicity studies indicated that in the absence of an oscillating magnetic field, cell viability was not affected at concentrations of up to $0.6 \mathrm{mg}$ iron oxide/mL. MFH resulted in a significant decrease in cell viability when exposed to a magnetic field for 120 minutes and allowed to rest for 48 hours, compared with similar field applications, but with shorter resting time. The results presented here suggest that MFH most likely induces apoptosis in both cell types. When compared with HWH, MFH produced a significant reduction in cell viability, and these effects appear to be cell-type related.
\end{abstract}

Keywords: magnetic fluid hyperthermia, carboxymethyl dextran magnetite, cell death, apoptosis

\section{Introduction}

The physical, chemical, thermal, and mechanical properties of magnetic nanoparticles make them suitable for biomedical applications including cell labeling, targeting and separation, drug delivery, magnetic resonance imaging, and hyperthermia. ${ }^{1-6}$ For these applications, particles must have combined properties of high magnetic saturation, biocompatibility, and suitable functionalization at the surface. ${ }^{7}$ One promising biomedical approach using magnetic nanoparticles is magnetic fluid hyperthermia $(\mathrm{MFH})$, where cancer tissue placed in contact with magnetic nanoparticles is exposed to an alternating magnetic field.

During this process, heat is generated due to magnetic hysteresis loss. ${ }^{8}$ The increase in temperature will depend on the magnetic properties of the material, the strength of the magnetic field, the frequency of oscillation, and the cooling capacity of the blood flow in the tumor site. ${ }^{7}$ Nanoplatforms such as magnetite-dextran nanoparticles, magnetic cationic liposomes, and aminosilane iron oxide nanoparticles have been studied in vitro, in vivo, and in human trials, with success. ${ }^{9-16}$ In humans, treatment was tolerated by patients with minor or no side effects, whereas in vivo analysis demonstrated successful tumor remission. 
Although significant work has been performed in the area of MFH in vitro, little has been done to compare the effects of MFH with conventional hyperthermia treatments such as hot water. Jordan et al were the first to study in vitro MFH caused by a suspension of magnetic nanoparticles, and compared its effectiveness to hyperthermia using a hot water bath. ${ }^{17,18}$ Results indicated differences regarding the effects on the viability of WiDr (human colonic adenocarcinoma) and BT-20 (human mammary adenocarcinoma) cells when treated by MFH and hot water. Silane-coated nanoparticles were used with the BT-20 cells, whereas dextran-coated nanoparticles where used with the WiDr cells. Results with the WiDr cell line indicated that there was no difference in reduction in cell viability for the two treatments, whereas the BT-20 cells did demonstrate a significant difference in reduction in viability due to MFH when compared with hotwater hyperthermia (HWH). Such differences are difficult to explain when dealing with different cell lines and different types of nanoparticle functionalization. Silane-magnetite nanoparticles showed higher internalization in BT-20 when compared with dextran ferrite particles on WiDr. ${ }^{18}$ Higher levels of magnetic nanoparticle internalization could promote additional damage and injury to the cells when submitted to a magnetic field, generating a further effect on cell viability. Thus, it is unclear whether the observed differences are due to the use of two different types of particles or due to the differences between cell lines.

Because of the substantial interest in hyperthermia using traditional techniques in the clinical literature, and the potential of MFH to deliver heat locally, potentially avoiding side effects associated with regional and systemic forms of hyperthermia treatment, there is still interest in direct comparisons between hyperthermia and MFH. ${ }^{19-20}$ This is further motivated by debate in the literature as to whether hyperthermia at the nanoscale poses any advantages over traditional forms of hyperthermia. ${ }^{21}$ This work seeks to quantify the differences between MFH and conventional HWH treatment using a temperature range of $41^{\circ} \mathrm{C}-46^{\circ} \mathrm{C}$, which is commonly considered to be the range of hyperthermia. For this purpose, two cell models, Caco-2 (human epithelial colorectal adenocarcinoma cells) and MCF-7 (human breast cancer cells) and one nanoparticle platform composed of co-precipitated iron-oxide based magnetic nanoparticles functionalized with carboxymethyl dextran, henceforth referred to as IO-CMDX, were employed. A series of MFH and hyperthermia exposure sequences were designed and performed in both cell lines to establish a coherent comparison basis. These scheduled treatments took into consideration field exposure time and resting times after treatment. Such parameters were varied to establish differences. Potential cell death mechanisms, such as apoptosis or necrosis, were also investigated.

\section{Materials and methods Materials for nanoparticle synthesis}

Iron (II) chloride tetrahydrate, iron (III) chloride hexahydrate, ammonium hydroxide $(29 \% \mathrm{v} / \mathrm{v})$, tetramethylammonium hydroxide $(25 \% \mathrm{w} / \mathrm{v})$, and carboxymethyl dextran sodium salt were obtained from Sigma Aldrich (St. Louis, MO). Nitric acid $\left(\mathrm{HNO}_{3}\right)$ was obtained from Fisher Scientific (Pittsburg, PA).

\section{Synthesis of IO-CMDX}

Iron oxide nanoparticles were synthesized through co-precipitation of aqueous suspensions of ferric and ferrous chloride ions. ${ }^{22}$ They were then functionalized with carboxymethyl dextran to improve particle dispersion in cell culture medium. To obtain nanoparticles, an aqueous solution of ferric chloride $(0.36 \mathrm{M})$ was vigorously stirred with a solution of ferrous chloride $(0.18 \mathrm{M})$, in the presence of a nitrogen stream, to avoid oxidation of the iron ions prior to precipitation. Ammonium hydroxide was added to the iron solution. The product of this reaction quickly changed color from brown to black, which is indicative of magnetite formation. This solution was heated to $80^{\circ} \mathrm{C}$ for approximately 1 hour under continuous stirring at $\mathrm{pH} 8.0$ to promote reduction and precipitation. The solution was left to cool overnight. The iron oxide solution was centrifuged for 5 minutes at $1800 \mathrm{rpm}$, and the supernatant was discarded. The precipitated particles were peptized with $0.5 \mathrm{M} \mathrm{HNO}_{3}$. The peptized iron oxide was centrifuged for 15 minutes at $3500 \mathrm{rpm}$ and then resuspended in water. A $0.013 \mathrm{M}$ solution of carboxymethyl dextran at $\mathrm{pH} 11.0$ was added. The final solution was maintained at a $\mathrm{pH}$ range of 3.0-5.0 using $1 \mathrm{M} \mathrm{HCl}$. The solution was mixed at $200 \mathrm{rpm}$ for a period of 48 hours. The magnetic colloidal suspension was washed with an equivalent volume of ethanol at $3500 \mathrm{rpm}$ for 10 minutes to precipitate the nanoparticles and remove the unattached carboxymethyl dextran. The precipitated particles were dialyzed to a conductivity of $10 \mu \mathrm{S} / \mathrm{cm}$ using de-ionized water and a dialysis membrane with a molecular weight cutoff of $20 \mathrm{kDa}$. Finally, the nanoparticles were dried in a vacuum oven.

\section{Nanoparticle suspension}

Nanoparticles were autoclaved for 60 minutes at a temperature of $121^{\circ} \mathrm{C}$ and 18 psi. Before experiments with cells, 
particles were suspended in supplemented Dulbecco's Modified Eagle's Medium (DMEM) (Sigma, St. Louis, MO) with phenol red and with $10 \%$ of fetal bovine serum (FBS) (Invitrogen, Carlsbad, CA). The final particle concentration was $10 \mathrm{mg}$ particles $/ \mathrm{mL}(0.6 \mathrm{mg}$ iron oxide $/ \mathrm{mL})$. For cytocompatibility analysis, four dilutions of $0.3,0.6$, 0.9 , and $1.5 \mathrm{mg}$ iron oxide/mL suspensions in DMEM/FBS were prepared. For MFH, a concentration of 0.6 iron oxide/ $\mathrm{mL}$ was used.

\section{Nanoparticle characterization}

The weight fraction of iron oxide core in the IO-CMDX nanoparticles was determined through thermogravimetric analysis using a TA Instruments TA-2950 Thermogravimetric Analyzer (TA Instruments, Newcastle, DE) with a heating rate of $10^{\circ} \mathrm{C} / \mathrm{min}$ under air flow. The mass fraction of iron oxide was calculated from the remnant mass at a temperature of $600^{\circ} \mathrm{C}$, divided by the initial sample mass. The hydrodynamic diameter of the resulting IO-CMDX nanoparticles was determined by dynamic light scattering (DLS) using a Brookhaven Instruments BI-90Plus Particle Size Analyzer (90 ${ }^{\circ}$ scattering angle) (Brookhaven Instrument Corp, Holtsville, NY). Measurements were performed with particles suspended after autoclaving using $0.1 \% \mathrm{w} / \mathrm{w}$ suspensions in de-ionized water. The capacity of the nanoparticles to dissipate energy as heat upon application of an oscillating magnetic field was parameterized through the so-called specific absorption rate (SAR). ${ }^{23}$ Measurements were made by placing $1 \mathrm{~mL}$ of IO-CMDX suspension at 0.6 iron oxide $/ \mathrm{mL}$ in a thermally insulated nonmetallic/nonmagnetic container. The sample was allowed to reach thermal equilibrium with the surroundings, and then a magnetic field of 20 $\mathrm{kA} / \mathrm{m}$ and $238 \mathrm{kHz}$ was applied using a four-turn induction coil connected to an RDO Induction HFI 3-135/400 (RDO Enterprises Inc, Washington, NJ). Temperature was monitored as a function of time using a ThermoVision ${ }^{\mathrm{TM}}$ A20 thermal imaging camera (FLIR systems, Boston, MA). The SAR value of the nanoparticles was calculated according to:

$$
S A R=\hat{C} \frac{m_{\text {sample }}}{m_{\text {iron oxide }}}\left(\frac{d T}{d t}\right)_{t \rightarrow 0}
$$

where $\hat{C}$ is the specific heat capacity, assumed equal to that of water, $m_{\text {sample }}$ and $m_{\text {iron oxide }}$ are the total sample mass and iron oxide mass, respectively, and $d T / d t_{t \rightarrow 0}$ is the initial rate of increase in temperature upon application of the magnetic field.

\section{Caco-2 cell culture}

Caco-2 cells were purchased from the American Type Culture Collection (Rockville, MD). Cells were cultured on $75 \mathrm{~cm}^{2}$ cell culture flasks (canted neck) (Costar Corning, Lowell, MA) at a concentration of 250,000 cells/ flask, using DMEM containing 10\% FBS, 1\% nonessential amino acids (Invitrogen), 100 units $/ \mathrm{mL}$ of penicillin (Sigma), and $100 \mu \mathrm{g} / \mathrm{mL}$ of streptomycin (Sigma). Cells were maintained in a controlled atmosphere at $37^{\circ} \mathrm{C}, 95 \%$ relative humidity, and $5 \% \mathrm{CO}_{2}$. The culture medium was changed every other day for approximately 5-6 days until cells reached approximately $80 \%-90 \%$ confluency. Cells were detached from the culturing flask by trypsinization, resuspended in culture media, and counted.

\section{MCF-7 cell culture}

MCF-7 cells were purchased from American Type Culture Collection (Rockville, MD). Cells were cultured as described above, but with a concentration of $1 \times 10^{6}$ cells/flask.

\section{Cytocompatibility analysis}

Cells were seeded at a concentration of $10,000 \mathrm{cells} / \mathrm{cm}^{2}$ for Caco-2 and 40,000 cells/ $\mathrm{cm}^{2}$ for MCF-7 in 96-well assay plates of $0.71 \mathrm{~cm}^{2} /$ well (Costar Corning) and grown for 1 week in supplemented DMEM with phenol red, with particle concentrations of $1.0,2.0,3.0$, and $5.0 \mathrm{mg} / \mathrm{mL}$ at $37^{\circ} \mathrm{C}$ and $5 \% \mathrm{CO}_{2}$. Pure DMEM was used as a negative control and $1.5 \%$ hypochlorite solution was used as a positive control for cell viability. At the end of the week, nanoparticle suspensions were removed and the 96-well assay plate was rinsed with Hank's balanced salt solution (Sigma). For cell viability analysis, the cells were incubated at $37^{\circ} \mathrm{C}$ and $5 \% \mathrm{CO}_{2}$ with CellTiter-BlueTM (Promega, Madison, WI). Cell viability was analyzed with a spectrofluorometer (SpectraMax Gemini EM, Molecular Devices, Sunnyvale, CA) with an excitation wavelength of $560 \mathrm{~nm}$ and an emission wavelength of $590 \mathrm{~nm}$ required for the aforementioned assay. Cell viability results were interpreted as the viability ratio as a function of nanoparticle concentration. The viability ratio was calculated by normalizing all relative fluorescent unit values with the relative fluorescent unit value of the negative control (cells with DMEM).

\section{Hyperthermia using a hot water bath}

Cells were cultured as described. They were detached from the culturing flask by trypsinization, resuspended in culture media, and counted. A quantity of $3 \times 10^{6}$ cells was seeded on a $20 \mathrm{~mL}$ test tube and suspended to a final volume of $10 \mathrm{~mL}$ 
with DMEM $+10 \%$ FBS. The test tube was then placed in a hot water bath at constant temperature $\left(41^{\circ} \mathrm{C}\right.$ or $\left.45^{\circ} \mathrm{C}\right)$ for a period of 2 hours. Samples were gently shaken at short time intervals. After hyperthermia treatment, the cells' viability was quantified and the presence of apoptotic markers was studied as described below.

\section{$\mathrm{MFH}$}

Cells were cultured as described above. Cells were detached from the culturing flask by trypsinization, resuspended in culture media, and counted. A concentration of $3 \times 10^{6}$ cells was placed in a $20 \mathrm{~mL}$ test tube and suspended to a final volume of $15 \mathrm{~mL}$ with DMEM + 10\% FBS (negative control) or with a concentration of $0.6 \mathrm{mg} / \mathrm{mL}$ of IO-CMDX nanoparticle suspension. The test tube was then inserted into a four-turn induction coil connected to an RDO induction HFI 3-135/400 (RDO Enterprises Inc, Washington, NJ) and bubbled with air to maintain cells suspended during magnetic field application.

The magnetic field was applied for a period of 1 hour or 2 hours with a magnetic field amplitude of $20 \mathrm{kA} / \mathrm{m}$ and frequency of $238 \mathrm{kHz}$. Temperature was monitored using a ThermoVision ${ }^{\mathrm{TM}}$ A20 thermal imaging camera (FLIR Systems, Boston, MA) and maintained between $42^{\circ} \mathrm{C}$ and $45^{\circ} \mathrm{C}$. Samples took an average of 20 minutes to reach the desired temperature, after which exposure time started. After the magnetic field treatment the cell's viability and apoptosis were analyzed as described below.

\section{Cell viability and apoptosis}

The effect of hyperthermia on cell culture was analyzed by performing cell viability and testing for the presence of apoptotic markers. These assays were performed immediately, 24 hours, or 48 hours after hyperthermia application. The assays at 24 and 48 hours were performed to allow cell death to occur. Cell viability was measured by cell-counting using trypan blue. Cells were counted before and after hyperthermia application. A 1:1 dilution of cell sample and trypan blue dye was used for cell counting using a hematocytometer. Stained cells were considered dead. Viability results were interpreted as the ratio of viable cells after treatment and viable cells before treatment. Final results were normalized with the negative control. The presence of apoptotic markers was analyzed using the ApoPercentage assay (Biocolor, County Antrium, UK). This assay stains cells when the inner plasma membrane leaflet has been exposed, a classic marker of apoptosis. Cells were put in contact with the assay with an ApoPercentage concentration of $5 \%$ for a period of 30 minutes. The apoptotic and nonapoptotic cells were counted using a hematocytometer. The results were interpreted as the apoptosis ratio over the viability ratio.

\section{Data analysis}

Unless otherwise stated, the sample size was $\mathrm{n}=3$. $T$-test (two- tailed distribution, two-sample with unequal variances) analysis was employed to determine any significance in observed data. A $P$-value of $<0.05$ was considered statistically significant.

\section{Results}

\section{Particle characterization}

The hydrodynamic diameter of the IO-CMDX was found to be $72.2 \pm 4.5 \mathrm{~nm}$ according to DLS. Thermogravimmetric analysis indicated that it consisted of $27 \%$ by weight inorganic core and $73 \%$ by weight organic material, on the basis of the remnant mass after heating to $600^{\circ} \mathrm{C}$. The SAR of the particles was $245.26 \mathrm{~W} / \mathrm{g}$ at a magnetic field amplitude of $20 \mathrm{kA} / \mathrm{m}$ and frequency of $238 \mathrm{kHz}$. Particle samples were also tested for stability in culture media and after autoclaving. Results indicated that particle samples used for hyperthermia experiments consisting of a particle concentration of $0.6 \mathrm{mg}$ of iron oxide $/ \mathrm{mL}$ were stable for the experimental time frame, and their size in suspension was not affected by the autoclaving process. Note that the particles used in this study are similar to those reported in our recent work, in which additional chemical, physical, and magnetic characterization is provided. ${ }^{24}$

\section{Cytocompatibility}

Cytocompatibilty analyses were first performed to rule out the effect of nanoparticle toxicity during MFH. Experiments were performed during cell seeding for a period of 1 week using two different cell culture models (Caco-2 and MCF-7). Cell viability analysis of IO-CMDX on both cell culture lines started to demonstrate cytotoxic effects at concentrations above $0.9 \mathrm{mg}$ iron oxide $/ \mathrm{mL}$ (see Figure 1).

\section{$\mathrm{MFH}$ and $\mathrm{HWH}$}

Two hyperthermia protocols were applied, HWH and MFH, with the purpose of comparing traditional hyperthermia with that resulting from energy dissipation from magnetic nanoparticles. Experiments were performed to measure the immediate and long-term impact of the hyperthermia treatments in cell viability using two cell lines, Caco-2 and MCF-7.

$\mathrm{HWH}$ experiments were performed at two temperatures, $41^{\circ} \mathrm{C}$ and $45^{\circ} \mathrm{C}$, with an exposure period of 1 or 2 hours. 


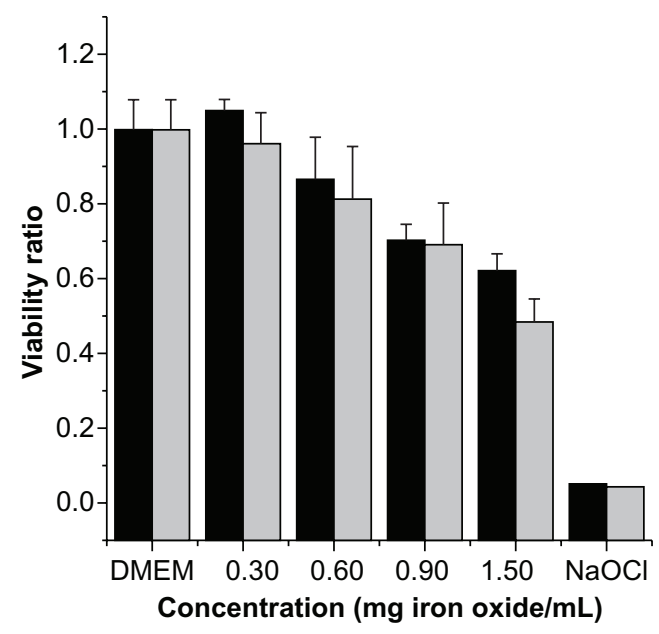

Figure I Viability analysis of iron oxide nanoparticles coated with carboxymethyl dextran as a function of concentration.

Notes: corresponds to Caco-2 cells and corresponds to MCF-7. Each bar represents an average of $n=12 \pm$ standard deviation.

Abbreviation: DMEM - cells maintained in the incubator.

These two temperatures were selected to examine possible differences between the minimum and maximum temperature of the established hyperthermia range. Cell viability was analyzed immediately after application and 24 and 48 hours after hyperthermia treatment. Apoptosis analysis was also performed on all treatments to investigate whether hyperthermia promoted apoptosis on our cell models. Apoptosis results are presented as the ratio between the apoptosis ratio and the viability ratio. Magnetic fluid hyperthermia was performed by varying the time of magnetic field application, with a magnetic field amplitude of $20 \mathrm{kA} / \mathrm{m}$ and frequency of $238 \mathrm{kHz}$. Temperature was continuously monitored during magnetic field application with an infrared camera and an alcohol thermometer. The average temperature recorded during these experiments was always between $42^{\circ} \mathrm{C}$ and $45^{\circ} \mathrm{C}$.

To compare the thermal doses supplied to the cells with the two treatments, the thermal dose was calculated as proposed by Dewey et al. ${ }^{20}$ The thermal dose in equivalent minutes at $43^{\circ} \mathrm{C}$ was 420 minutes for $\mathrm{HWH}$ and 450 minutes for MFH; that is, the HWH protocol actually resulted in a slightly higher thermal dose compared with our MFH protocol, when using the equivalent minutes dose metric of Dewey. ${ }^{25}$ However, as discussed below, results indicated that for both cell models, MFH induced a more significant reduction in cell viability compared with $\mathrm{HWH}$.

Viability and apoptosis analysis using $\mathrm{HWH}$ at $41^{\circ} \mathrm{C}$ on cells were performed (data not shown). Data indicated a slight decrease in cell viability when compared with the negative control. This suggests that hyperthermia at $41^{\circ} \mathrm{C}$ does not cause a significant apoptotic effect in the two cell models used in this study. To further investigate the effects of MFH and $\mathrm{HWH}$, four different schedules were performed, as follows:

- Schedule A - analysis immediately after 2-hours application

- Schedule B - analysis performed 24 hours after 2-hours application

- Schedule $\mathrm{C}$ - analysis performed 48 hours after 2-hours application

- Schedule D - analysis performed 48 hours after 1-hour application.

These schedules were designed to study the immediate and long-term effects of HWH and MFH on cell viability and apoptosis. Three different controls were always performed for each experiment:

- DMEM - cells maintained in the incubator

- MF - magnetic field application to cells without particles

- Cytotoxicity - cells in contact with particle suspension without the application of a magnetic field.

An average of all the corresponding controls are reported and normalized by the results of cells maintained in the incubator.

Results indicated that viability of Caco-2 cell controls (Figure 2) was over $90 \%$ in all cases, and there was no statistically significant difference between the experimental controls. Apoptosis level was between $20 \%$ and $25 \%$

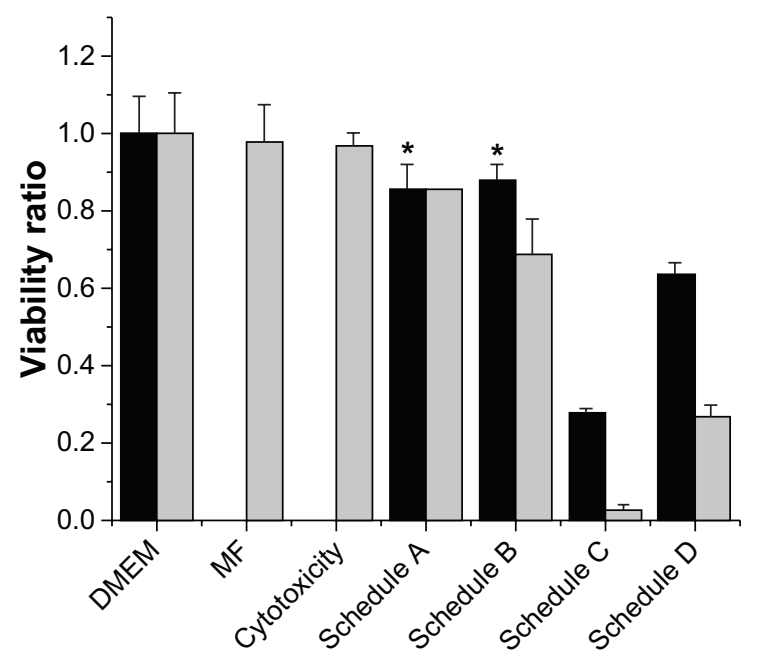

Figure 2 Viability analysis of Caco-2 cells exposed to various modes of hyperthermia.

Notes: corresponds to hot water hyperthermia and corresponds to magnetic fluid hyperthermia. Schedule A: Viability measured immediately after 2 hours of application; Schedule B: Viability measured 24 hours after 2 hours of application; Schedule $C$ : Viability measured 48 hours after 2 hours of treatment; Schedule D: Viability measured 48 hours after I hour of treatment. *Statistically similar with $P=0.62$.

Abbreviations: DMEM - cells maintained in the incubator; MF - magnetic field application to cells without particles. Cytotoxicity - cells in contact with particle suspension without the application of a magnetic field. 


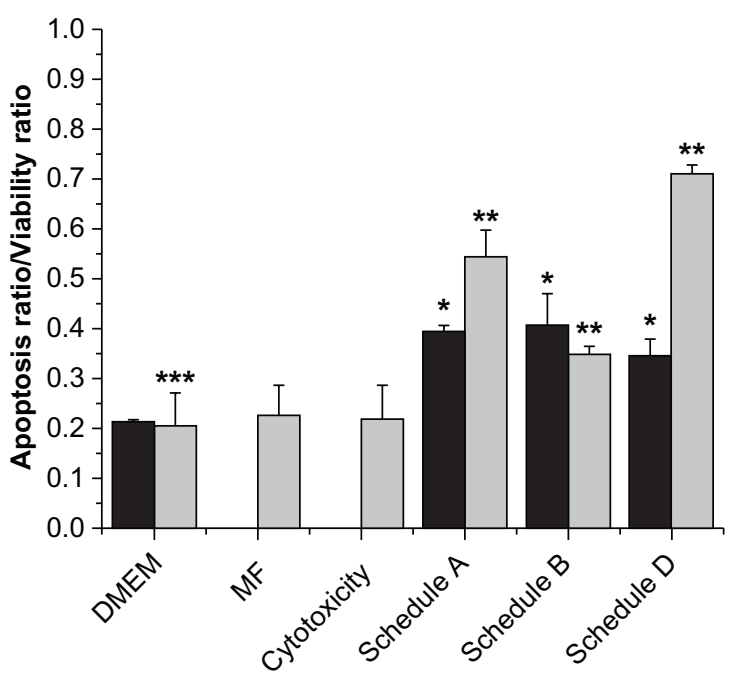

Figure 3 Apoptosis ratio over viability ratio for Caco-2 cells exposed to various modes of hyperthermia.

Notes: corresponds to hot water hyperthermia and corresponds to magnetic fluid hyperthermia. Schedule A: Viability measured immediately after 2 hours of application; Schedule B: Viability measured 24 hours after 2 hours of application; Schedule D: Viability measured 48 hours after I hour of treatment. *Statistically similar with $P=0.65$ when compared to control; **Statistically different with $P=0.008$ when compared to various hot water hyperthermia treatments denoted by *; ***Statistically different with $P=0.02$ when compared those bars containing various magnetic hyperthermia treatments denoted by $* *$.

Abbreviation: DMEM - cells maintained in the incubator; MF - magnetic field application to cells without particles. Cytotoxicity - cells in contact with particle suspension without the application of a magnetic field.

(Figure 3) for HWH and MFH. In the case of the MCF-7 cell line, viability results were also over $90 \%$ for all cases (Figure 4), and apoptosis levels were approximately $15 \%$ (Figure 5). Experiments performed using schedule A (2-hours application and no resting time) in Caco-2 cells showed a decrease in cell viability to $\sim 85 \%$ after $\mathrm{HWH}$ and to $\sim 75 \%$ after MFH (Figure 3, 'Schedule A'). When the viability was measured 24 hours after 2 -hours hyperthermia (schedule B), the HWH treatment did not show any statistically significant difference $(P=0.62, \alpha=0.05)$ when compared with HWH using schedule A. A resting time of 48 hours after hyperthermia resulted in the reduction of cell viability to $\sim 25 \%$ for $\mathrm{HWH}$ and to $\sim 2 \%$ for MFH (Figure 2, 'Schedule C'). Similar experiments were conducted for a shorter period of hyperthermia exposure. Schedule D, which consisted of 1 hour of hyperthermia and a resting time of 48 hours, had a greater effect on cell viability in both methods, HWH and MFH, when compared with schedules $\mathrm{A}$ and B. A cell viability of $\sim 65 \%$ was obtained for $\mathrm{HWH}$ and $\sim 25 \%$ for $\mathrm{MFH}$.

Apoptosis analysis was also performed on Caco-2 cells after each of the treatments (Figure 3), except for schedule $\mathrm{C}$ since most cells were dead at that point. Apoptosis after

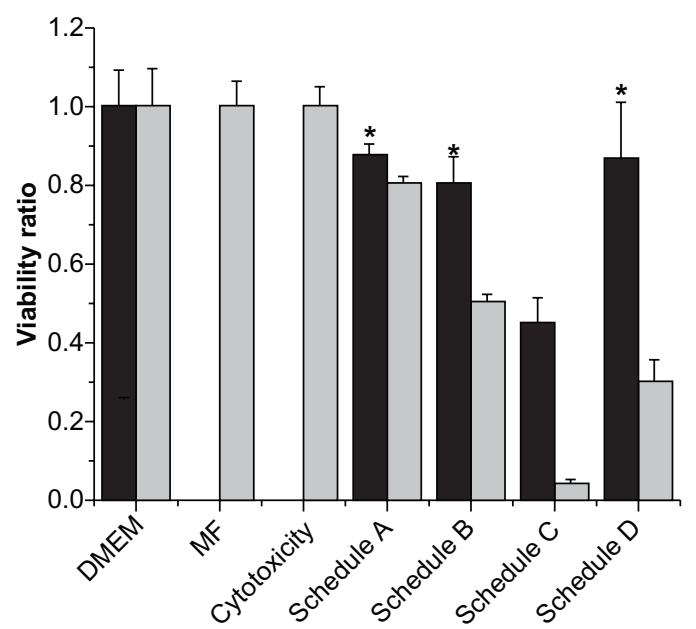

Figure 4 Viability analysis of MCF-7 cells exposed to various modes of hyperthermia. Notes: corresponds to hot water hyperthermia and corresponds to magnetic fluid hyperthermia. Schedule A: Viability measured immediately after 2 hours of application; Schedule B: Viability measured 24 hours after 2 hours of application; Schedule C: Viability measured 48 hours after 2 hours of treatment; Schedule D: Viability measured 48 hours after I hour of treatment. *Statistically similar with $P=0.15$.

Abbreviation: DMEM - cells maintained in the incubator; MF - magnetic field application to cells without particles. Cytotoxicity - cells in contact with particle suspension without the application of a magnetic field.

HWH was statistically similar for all treatments $(P=0.65$, $\alpha=0.05$ ) but different from controls, exhibiting an increase to $\sim 35 \%-40 \%$. On the other hand, for MFH, schedule A showed an apoptosis of $\sim 55 \%$, schedule B an apoptosis of $\sim 35 \%$, and schedule $\mathrm{D}$ an apoptosis of $\sim 70 \%$, which have statistically significant differences from the negative control $(P=0.02, \alpha=0.05)$ and $\operatorname{HWH}(P=0.008, \alpha=0.05)$.

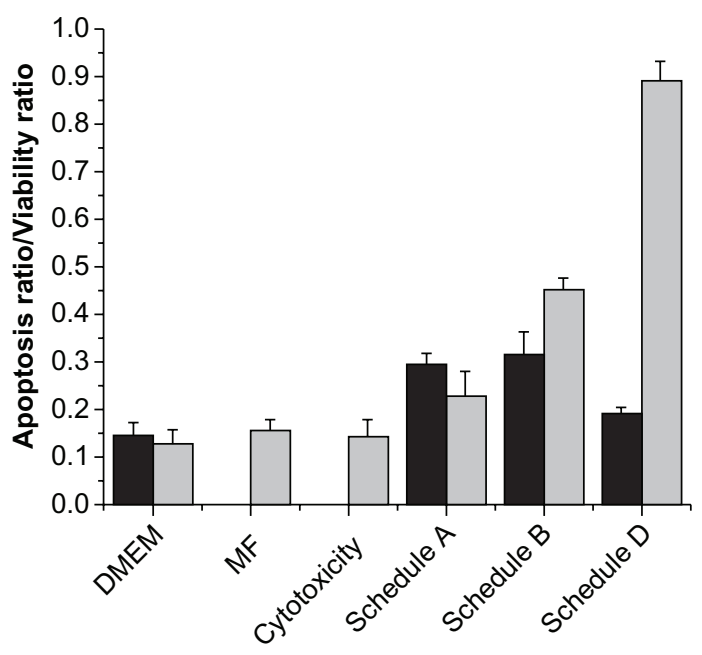

Figure 5 Apoptosis ratio over viability ratio for MCF-7 cells exposed to various modes of hyperthermia.

Notes: corresponds to hot water hyperthermia and corresponds to magnetic fluid hyperthermia. Schedule A: Viability measured immediately after 2 hours of application; Schedule B: Viability measured 24 hours after 2 hours of application; Schedule D: Viability measured 48 hours after I hour of treatment.

Abbreviation: DMEM - cells maintained in the incubator; MF - magnetic field application to cells without particles. Cytotoxicity - cells in contact with particle suspension without the application of a magnetic field. 
Similar experiments were performed on MCF-7 cells in order to establish whether the observed phenomenon was specific to the Caco-2 cell line. Results for HWH for all of the treatments, except schedule $\mathrm{C}$, demonstrated a reduction in cell viability to $\sim 85 \%$, with no statistically significant difference between treatments $(P=0.15$ for $\alpha=0.05$ ). HWH using schedule C (2 hours of application and a resting time of 48 hours) resulted in a reduction in cell viability to $\sim 45 \%$ (see Figure 4 ). In the case of MFH, there was a significant difference in reduction in cell viability for schedules A, B, C, and D, for which cell viability decreased to $\sim 80 \%, \sim 50 \%, \sim 5 \%$, and $\sim 30 \%$, respectively. Apoptosis analysis in MCF-7 cells showed an increase to $\sim 30 \%$ for schedules A and B and to $20 \%$ for schedule C after $\mathrm{HWH}$ (Figure 5). On the other hand, the resulting apoptosis for MCF-7 after MFH was $\sim 25 \%$ for schedule A, $\sim 45 \%$ for schedule B, and $\sim 90 \%$ for schedule D. Schedule C was not measured since most cells were dead.

\section{Discussion}

This work intended to quantify differences between conventional hyperthermia (HWH) and MFH. Cytocompatibility analysis indicated that there was a reduction in cell viability as the amount of iron oxide in suspension increased. This reduction in cell viability may be attributed to loss of colloidal stability as significant precipitation of the particles was observed at higher concentrations. Recently, Miles et $\mathrm{al}^{26}$ examined the colloidal stability of nanoparticles in the presence of phosphate based buffers. Results demonstrated that carboxylic acid groups were displaced by the phosphate ions promoting particle aggregation. Since the DMEM formulation possesses a high concentration of phosphate ions $(0.109 \mathrm{~g} / \mathrm{L}$ of sodium phosphate monobasic), this was most likely the cause for particle aggregation at high concentrations. Loss of viability may be due to potential physical damage caused by precipitated particles. As such, a concentration of $0.6 \mathrm{mg}$ iron oxide $/ \mathrm{mL}$ was selected for MFH experiments to ensure that the observed effects were solely due to the effects of MFH.

Experimental controls performed on cell viability and apoptosis analysis demonstrated that neither magnetic nanoparticles alone nor the magnetic field alone affected cell viability under the conditions tested. By comparing the 1-hour and 2-hours MFH treatments, it was observed that there was a difference in viability when measured immediately, 24 hours, or 48 hours after treatment. As expected, exposure to hyperthermia for 2 hours resulted in a greater effect on cell viability when compared with exposure for 1 hour. The ability of cells to protect themselves from heat stress by producing heat shock proteins could be the reason for the need to apply a longer period of heat. ${ }^{27}$ By comparing the results between MFH and HWH, it can be observed that there was a greater decrease in cell viability with $\mathrm{MFH}$, compared with $\mathrm{HWH}$, for both cell types. Jordan et al ${ }^{17,18}$ reported that WiDr cells treated by MFH and HWH did not present a difference in viability, whereas BT-20 cells did show a significant difference in cell viability after MFH in comparison with HWH. However, in their case two different cell models with two different particles were employed. As a result, direct comparisons are difficult to make. Also, they performed MFH on a cell pellet, where only cells on the surface of the pellet will have direct contact with the particles. Our experiments were conducted with cells in suspension; hence, nanoparticles and cells were in direct contact during the treatment. More importantly, studies in both cell lines were conducted using similarly coated nanoparticles. This allows for a more direct comparison between HWH and MFH. Our results indicated that for both cell models MFH had a greater effect on cell viability when compared with HWH. These results indicate that MFH is an effective tool to target heat to desired areas while potentially overcoming current challenges of traditional hyperthermia treatments.

\section{Conclusion}

This work explored differences between conventional hyperthermia (HWH) and MFH. Cytotoxicity experiments demonstrated that as colloidal stability was lost, an increase in cytotoxic effects was observed when either of the cell lines were exposed to IO-CMDX nanoparticles. Subsequent experiments were conducted with particle concentrations which did not result in loss in cell viability in the absence of a magnetic field. HWH experiments suggested that apoptosis was induced in both cell models at $45^{\circ} \mathrm{C}$. The apoptotic effect was slow and its effects on viability were not observed until 48 hours after 2 hours of treatment. On the other hand, an effect due to MFH on cell viability was detected 24 hours after 2 hours of treatment, suggesting that MFH had a more significant effect on cell viability than HWH. When cell viability was compared between $\mathrm{HWH}$ and $\mathrm{MFH}$, results clearly indicated that there is a significant additional effect on cell viability due to MFH when compared with hot water treatment, providing additional evidence of the promising use of magnetic nanoparticles for localized hyperthermia applications. The mechanisms for the observed differences are still unknown. 


\section{Acknowledgment}

This work was supported by the US National Science Foundation (Grant No. CBET-0609117).

\section{Disclosure}

The authors report no conflicts of interest in this work.

\section{References}

1. Krishnan KM. Biomedical nanomagnetics: a spin through possibilities in imaging, diagnostics, and therapy. IEEE Trans Magn. 2010;46(7): 2523-2558.

2. Latorre M, Rinaldi C. Applications of magnetic nanoparticles in medicine: magnetic fluid hyperthermia. P R Health Sci J. 2009;28(3): $227-238$.

3. Jain P, Lee K, El-Sayed I, El-Sayed M. Calculated absorption and scattering properties of gold nanoparticles of different size, shape, and composition: applications in biological imaging and biomedicine. J Phys Chem B. 2006;110(14):7238-7248.

4. Merritt WM, Lin YG, Spannuth WA, et al. Effect of interleukin- 8 gene silencing with liposome-encapsulated small interfering RNA on ovarian cancer cell growth. J Nat Cancer Inst. 2008;100(5): 359-372.

5. Brigger I, Dubernet C, Couvreur P. Nanoparticles in cancer therapy and diagnosis. Adv Drug Deliv Rev. 2002;54(5):631-651.

6. Ferrari M. Cancer nanotechnology: opportunities and challenges. Nat Rev Cancer. 2005;5(3):161-171.

7. Gupta A, Gupta M. Synthesis and surface engineering of iron oxide nanoparticles for biomedical applications. Biomaterials. 2005;26(18): 3995-4021.

8. Rosensweig R. Heating magnetic fluid with alternating magnetic field. J Magn Magn Mater. 2002;252(1-3):370-374.

9. Wada S, Yue L, Tazawa K, Furuta I, Nagae H, Takemori S, et al. New local hyperthermia using dextran magnetite complex (DM) for oral cavity: experimental study in normal hamster tongue. Oral Dis. 2001;7(3):192-195.

10. Jordan A, Scholz R, Maier-Hauff K, et al. The effect of thermotherapy using magnetic nanoparticles on rat malignant glioma. J Neurooncol. 2006 May;78(1):7-14

11. Kawai N, Futakuchi M, Yoshida T, et al. Effect of heat therapy using magnetic nanoparticles conjugated with cationic liposomes on prostate tumor in bone. Prostate. 2008;68(7):784-792.

12. Hilger I, Hiergeist R, Hergt R, Winnefeld K, Schubert H, Kaiser WA. Thermal ablation of tumors using magnetic nanoparticles: an in vivo feasibility study. Invest Radiol. 2002;37(10):580-586.

13. Maier-Hauff K, Rothe R, Scholz R, et al. Intracranial thermotherapy using magnetic nanoparticles combined with external beam radiotherapy: results of a feasibility study on patients with glioblastoma multiforme. J Neurooncol. 2007;81(1):53-60.
14. Johannsen M, Gneveckow U, Eckelt L, et al. Clinical hyperthermia of prostate cancer using magnetic nanoparticles: presentation of a new interstitial technique. Int J Hyperthermia. 2005;21(7):637-647.

15. Johannsen M, Gneveckow U, Thiesen B, et al. Thermotherapy of prostate cancer using magnetic nanoparticles: feasibility, imaging, and three-dimensional temperature distribution. Eur Urol. 2007;52(6): 1653-1661.

16. Thiesen B, Jordan A. Clinical applications of magnetic nanoparticles for hyperthermia. Int J Hyperthermia. 2008;24(6):467-474.

17. Jordan A, Wust P, Scholz R, et al. Cellular uptake of magnetic fluid particles and their effects on human adenocarcinoma cells exposed to AC magnetic fields in vitro. Int J Hyperthermia. 1996;12(6): $705-722$.

18. Jordan A, Scholz R, Wust P, et al. Endocytosis of dextran and silancoated magnetite nanoparticles and the effect of intracellular hyperthermia on human mammary carcinoma cells in vitro. J Magn Magn Mater. 1999;194:185-196.

19. Sun XR, Xing LG, Ling CC, et al. Biological rationales and clinical applications of temperature controlled hyperthermia - implications for multimodal cancer treatments. Curr Med Chem. 2010;17(27): 3045-3057.

20. Hurwitz MD. The effect of mild temperature hyperthermia on tumor hypoxia and blood perfusion: relevance for radiotherapy, vascular targeting and imaging. Int J Hyper. 2010;26(3):224-231.

21. Rabin Y. Is intracellular hyperthermia superior to extracellular hyperthermia in the thermal sense? Int J Hyper. 2002;18(3): 194-202.

22. Lefebure S, Bubois E, Cabuil V, Neveu S, Massart R. Monodisperse magnetic nanoparticles: preparation and dispersion in water and oils. J Mater Res. 1998;13(10):2975-2981.

23. Fortin JP, Wilhelm C, Servais J, Menager C, Bacri JC, Gazeau F. Size-sorted anionic iron oxide nanomagnets as colloidal mediators for magnetic hyperthermia. J Am Chem Soc. 2007;129:2628-2635.

24. Creixell M, Herrera AP, Latorre-Esteves M, Ayala V, Torres-Lugo M, Rinaldi C. Effect of graft method on the stability and cytotoxicity of carboxymethyl dextran coated magnetic nanoparticles. J Mater Chem. 2010;20:8539-8547.

25. Dewey WC. Arrhenius relationships from the molecule and cell to the clinic. Int J Hyper. 2009;25(1):3-20.

26. Miles WC, Goff JD, Huffstetler PP, et al. Synthesis and colloidal properties of polyether-magnetite complexes in water and phosphate-buffered saline. Langmuir. 2009;25(2):802-813.

27. Rylander MN, Feng Y, Bass J, Diller KR. Thermally induced injury and heat shock protein expression in cells and tissues. Ann NY Acad Sci. 2005;1066(1):222-242.
International Journal of Nanomedicine

\section{Publish your work in this journal}

The International Journal of Nanomedicine is an international, peerreviewed journal focusing on the application of nanotechnology in diagnostics, therapeutics, and drug delivery systems throughout the biomedical field. This journal is indexed on PubMed Central, MedLine, CAS, SciSearch $\AA$, Current Contents $₫ /$ Clinical Medicine,

\section{Dovepress}

Journal Citation Reports/Science Edition, EMBase, Scopus and the Elsevier Bibliographic databases. The manuscript management system is completely online and includes a very quick and fair peer-review system, which is all easy to use. Visit http://www.dovepress.com/ testimonials.php to read real quotes from published authors. 